\title{
TINGKAT PENDAPATAN DAN CURAHAN TENAGA KERJA PADA HUTAN RAKYAT DI KABUPATEN CIAMIS
}

\author{
BUDIMAN ACHMAD ${ }^{1 *}$, RIS HADI PURWANTO ${ }^{2}$, SAMBAS SABARNURDIN $^{2}$, \& SUMARDI $^{2}$ \\ ${ }^{1}$ Balai Penelitian Teknologi Agroforestry Ciamis \\ Jl. Raya Ciamis - Banjar Km. 4 PO. Box 5 Ciamis 46201 \\ *Email: budah59@yahoo.com \\ ${ }^{2}$ Fakultas Kehutanan Universitas Gadjah Mada \\ Jl. Agro No. 1, Bulaksumur, Sleman 55281
}

\begin{abstract}
Labor for private forest business has not been considered as an important production factor, which it makes the incomes from the private forests is unfavourable. The research was carried out to find out the incomes and labor allocation on private forests management as well as their correlation to farmer characteristics. Data were collected during May to July 2010 at Ciomas, Kalijaya and Kertaharja villages by interviewing sixty purposively selected farmers. Data were analyzed by qualitative and quantitative description. The results revealed that on the basis of land width ownership, the business earned an income to the farmers in Ciomas, Kalijaya and Kertaharja villages of Ciamis district were 6,641,783 IDR/year; 8,029,358 IDR/year, and 6,302,431 IDR/year, respectively. The labors in Kalijaya and Ciomas villages of Ciamis district were mostly allocated to manage private forests i.e. $104.77 \mathrm{MDW} / \mathrm{ha}$ year and 216.93 MDW/ha/year respectively as labors allocation in Kertaharja village were $210.05 \mathrm{MDW} / \mathrm{ha}$ /year. The potency of labor absorption level on agriculture sectors in Ciamis district defined as high, which was more than 75 percent. In relation to labor allocation, generally, ages of farmers had positive correlation while the land width had negative ones.
\end{abstract}

Keywords: absorption potency, labor allocation, income, men daily work (MDW), land width.

\section{INTISARI}

Tenaga kerja pada usaha hutan rakyat belum diperhitungkan sebagai faktor produksi yang penting sehingga menyebabkan pendapatan dari hutan rakyat kurang optimal. Penelitian ini dilaksanakan untuk mengetahui pendapatan dan alokasi tenaga kerja pada pengelolaan hutan rakyat serta hubungannya dengan karakter petani. Data dikumpulkan selama bulan Mei sampai Juli 2010 di Desa Ciomas, Desa Kalijaya, dan Desa Kertaharja melalui wawancara pada 60 petani yang dipilih secara sengaja. Data yang terkumpul kemudian dianalisa menggunakan analisis deskriptif kualitatif dan kuantitatif. Hasil penelitian menunjukkan bahwa berdasarkan rata-rata luas pemilikan hutan, usaha hutan rakyat menyumbangkan pendapatan pada petani di Desa Ciomas, Kalijaya, dan Kertaharja Kabupaten Ciamis berturut-turut sebesar Rp 6.641.783,-/th; Rp 8.029.358,-/th, dan Rp 6.302.431,-/th. Mayoritas tenaga kerja di Desa Kalijaya dan Desa Ciomas Kabupaten Ciamis dialokasikan untuk mengelola hutan rakyat yaitu sebesar 104,77 HKP/ha/th dan 216,93 HKP/ha/th, sedangkan alokasi tenaga kerja di Desa Kertaharja sebesar 210,05 HKP/ha/th. Potensi penyerapan tenaga kerja pada sektor pertanian di Kabupaten Ciamis tergolong tinggi, yakni lebih dari 75\%. Dalam hubungannya dengan alokasi tenaga kerja, secara umum usia petani mempunyai korelasi positif sedangkan luas lahan mempunyai korelasi negatif.

Kata kunci: potensi serapan, alokasi tenaga kerja, pendapatan, hari kerja pria (HKP), luas lahan. 


\section{PENDAHULUAN}

Tujuan akhir dari kebijakan ketenagakerjaan adalah untuk meningkatkan pendapatan masyarakat. Pada periode 2020-2030, Indonesia diproyeksikan mengalami bonus demografi dimana jumlah tenaga kerja usia produktif lebih banyak dari tenaga kerja usia tidak produktif. Melimpahnya tenaga kerja bisa menjadi potensi untuk mengelola hutan rakyat jika dikelola dengan baik. Sebaliknya jika tidak dikelola dengan baik, tenaga kerja yang melimpah bisa juga menjadi beban negara karena tidak tertampung oleh lapangan pekerjaan (Subroto, 2013). Di negara maju seperti Rumania, tenaga kerja usia muda telah mengalami kesulitan untuk memasuki pasar tenaga kerja. Akibatnya, menurut Vasile dan Irina (2014), laju pengangguran tenaga kerja usia muda meningkat dua kali lipat dibanding tenaga kerja usia tua. Di Eropa, menurut Gontkovičová et al. (2014), kelangkaan lapangan kerja menyebabkan tenaga kerja usia muda banyak yang terpaksa bekerja di luar kompetensinya (non-standard) atau bekerja pada bidang yang bukan menjadi pilihannya.

Besarnya pendapatan dipengaruhi oleh curahan waktu yang dikorbankan oleh petani dan keluarganya dalam beraktivitas usaha produktif yaitu kegiatan yang dilakukan oleh keluarga petani untuk menambah pendapatan. Sedangkan besarnya alokasi tenaga kerja dipengaruhi secara positif oleh banyaknya training kejuruan atau peningkatan kapasitas petani (Khan et al., 2013). Faktanya aktivitas produktif yang dilakukan oleh petani dan keluarganya cukup bervariasi, baik yang berbasis lahan seperti usaha sawah dan hutan rakyat maupun yang tidak berbasis lahan seperti usaha jasa. Banyaknya usaha produktif yang dilakukan petani berdampak terhadap alokasi curahan waktu kerja, sedangkan besarnya curahan waktu kerja akan mempengaruhi perkembangan usaha itu sendiri.
Pengelolaan hutan rakyat merupakan salah satu usaha petani berbasis lahan yang memerlukan input. Besarnya curahan tenaga kerja sebagai input yang dipergunakan pada pengelolaan hutan rakyat akan mempengaruhi pendapatan yang diperoleh keluarga petani. Curahan tenaga kerja dapat berasal dari dalam keluarga petani yaitu terdiri dari bapak, ibu, dan anak ataupun yang berasal dari buruh.

Tenaga kerja yang tersedia di pedesaan sebagian besar terserap pada kegiatan pertanian. Menurut data dari BPS, (2010) antara 75 s/d 98\% penduduk pedesaan di Kabupaten Ciamis bekerja di sektor pertanian, termasuk hutan rakyat. Luas hutan rakyat di Kabupaten Ciamis adalah 31.707,44 ha (BPS Kabupaten Ciamis, 2010) tersebar pada 36 kecamatan. Kecamatan tersebut terbagi dalam tiga region yaitu 19 kecamatan di region atas, 10 kecamatan di region tengah, dan 7 kecamatan di region bawah. Perbedaan karakteristik maupun biofisik ketiga region bisa memberi ciri tersendiri dalam pengelolaan hutan rakyat oleh petani.

Saat ini mayoritas hutan rakyat masih dikelola secara sederhana dicirikan oleh rendahnya input yang diberikan sehingga hasilnya belum maksimal. Usaha hutan rakyat merupakan salah satu lapangan pekerjaan potensial yang tersedia di desa, mudah diakses, dan dapat menyerap tenaga kerja. Hal ini terbukti ketika terjadi krisis ekonomi di Indonesia pada pertengahan tahun 1997, banyak usaha yang berskala besar justru tidak mampu bertahan. Sebaliknya, Usaha Kecil Menengah (UKM) seperti hutan rakyat tetap bertahan karena memiliki sifat resiliensi (Darusman et al., 2001).

Hutan yang dikelola secara intensif selain akan meningkat produktivitasnya, juga akan menyerap lebih banyak tenaga kerja. Akan tetapi, informasi mengenai curahan tenaga kerja pada usaha hutan rakyat masih sangat terbatas. Oleh karena itu, 
pertanyaan-pertanyaan yang akan dijawab pada penelitian ini adalah : (1) berapa pendapatan yang diperoleh petani dari usaha hutan rakyat ? (2) berapa besar curahan tenaga kerja pada usaha hutan rakyat? dan (3) bagaimana hubungan antara curahan tenaga kerja dengan karakteristik petani ?

\section{BAHAN DAN METODE}

Penelitian dilaksanakan pada bulan Mei sampai Juli 2010 di tiga desa yang dipilih secara sengaja yaitu Desa Ciomas Kecamatan Panjalu, Desa Kalijaya Kecamatan Banjarsari, dan Desa Kertaharja Kecamatan Cimerak dengan asumsi bahwa setiap desa mewakili region Kabupaten Ciamis yaitu :

1. Desa Ciomas mewakili region atas dengan rentang ketinggian lokasi di atas $400 \mathrm{~m} \mathrm{dpl}$

2. Desa Kalijaya mewakili region tengah dengan rentang ketinggian lokasi antara $200 \mathrm{~s} / \mathrm{d} 400 \mathrm{~m}$ $\mathrm{dpl}$.

3. Desa Kertaharja mewakili region bawah dengan rentang ketinggian lokasi kurang dari $200 \mathrm{~m}$ dpl.

Lokasi penelitian ditentukan secara sengaja berdasarkan keberadaan kelompok tani yang berhasil mengembangkan hutan rakyat secara swadaya. Setiap lokasi secara sengaja ditentukan 20 responden sehingga jumlah seluruhnya 60 responden. Pertimbangan yang digunakan adalah bahwa responden menjadi anggota kelompok tani yang aktif mengelola hutan rakyat pola agroforestri.

Jenis penelitian ini adalah penelitian sosial menggunakan pendekatan observasi. Data primer diperoleh secara langsung dari petani hutan rakyat melalui wawancara dengan berpedoman pada kuesioner yang telah dipersiapkan. Data sekunder dikumpulkan dari literatur yang revelan dengan penelitian dan laporan dari Kantor Desa, Dinas Kehutanan dan Perkebunan kabupaten Ciamis, Badan Pusat Statistik, dan laporan-laporan terkait lainnya.

Data yang terkumpul ditabulasi, dikelompokkan sesuai dengan tujuan dari kegiatan penelitian dan dianalisis seperti berikut :

Pendapatan petani, berasal dari berbagai sumber antara lain : usaha hutan rakyat, sektor jasa, mengolah sawah, kiriman dari keluarga, memelihara ternak, usaha kolam ikan dll. Pendapatan dari setiap sumber dihitung untuk jangka waktu satu tahun dan pendapatan total merupakan penjumlahan dari seluruh sumber.

Curahan tenaga kerja, adalah alokasi waktu kerja responden dan keluarganya yang digunakan untuk usaha hutan rakyat. Pemakaian ukuran jam kerja dianggap dapat memenuhi keperluan, tanpa memperhatikan kebiasaan kerja yaitu 8 (delapan) jam kerja dalam satu hari. Kelemahan pada ukuran ini antara lain, pekerja yang mempunyai keahlian, kekuatan, dan pengalaman kerja yang berbeda dinilai sama padahal pekerjaan dalam usahatani relatif beragam. Oleh karena itu, digunakan ukuran setara jam kerja pria (HKP) dengan menggunakan faktor konversi sebagai berikut (Pujianto, 2008; Simanjuntak, 2007):

a). 8 jam kerja tenaga kerja pria dewasa berumur $>15$ tahun $=1 \mathrm{HKP}$

b). 8 jam kerja tenaga kerja wanita dewasa berumur $>$ 15 tahun $=0,8 \mathrm{HKP}$

c). 8 jam kerja anak-anak berumur 10-15 tahun $=0,5$ HKP

Analisis korelasi digunakan untuk mengetahui kekuatan hubungan antara curahan tenaga kerja dengan umur, lama pendidikan, jumlah tanggungan, pengalaman usaha di hutan rakyat, dan luas kepemilikan lahan hutan rakyat. Keeratan hubungan antar peubah dianalisis menggunakan metode analisis Regresi Linier Berganda sebagai berikut: 


$$
\dot{Y}=a+b_{1} X_{1}+b_{2} X_{2}+b_{3} X_{3}+b_{4} X_{4}+b_{5} X_{5}
$$

Dimana:

$$
\begin{array}{ll}
\dot{Y} & =\text { Curahan tenaga kerja keluarga (HKP) } \\
\mathrm{a} & =\text { Intersep } \\
\mathrm{b}_{1} \mathrm{~s} / \mathrm{d} \mathrm{b}_{5} & =\text { Koefisien regresi } \\
\mathrm{X}_{1} & =\text { Usia responden (tahun) } \\
\mathrm{X}_{2} & =\text { Lama pendidikan responden (tahun) } \\
\mathrm{X}_{3} & =\text { Jumlah tanggungan keluarga (orang) } \\
\mathrm{X}_{4} & =\text { Lama pengalaman mengelola hutan } \\
& \text { rakyat (tahun) } \\
\mathrm{X}_{5} & =\text { Luas kepemilikan lahan hutan rakyat }
\end{array}
$$$$
\text { (Ha) }
$$

\section{HASIL DAN PEMBAHASAN}

\section{Identitas Responden}

Karakteristik responden meliputi : umur, lama pendidikan, jumlah tanggungan, jenis pekerjaan, dan

\begin{tabular}{|c|c|c|c|c|c|c|c|}
\hline \multirow[b]{2}{*}{ No } & \multirow[b]{2}{*}{ Uraian } & \multicolumn{2}{|c|}{ Region Atas } & \multicolumn{2}{|c|}{ Region Tengah } & \multicolumn{2}{|c|}{ Region Bawah } \\
\hline & & $\begin{array}{l}\text { Jumlah } \\
\text { (orang) }\end{array}$ & $\%$ & $\begin{array}{l}\text { Jumlah } \\
\text { (orang) }\end{array}$ & $\%$ & $\begin{array}{l}\text { Jumlah } \\
\text { (orang) }\end{array}$ & $\%$ \\
\hline 1 & Umur Petani (thn) & & & & & & \\
\hline & $20-29$ & 0 & 0 & 0 & 0 & 2 & 10 \\
\hline & $30-39$ & 2 & 10 & 3 & 15 & 3 & 15 \\
\hline & $40-49$ & 6 & 30 & 10 & 50 & 8 & 40 \\
\hline & $50-59$ & 9 & 45 & 6 & 30 & 4 & 20 \\
\hline & $60-69$ & 2 & 10 & 1 & 5 & 3 & 15 \\
\hline & $\geqslant 70$ & 1 & 5 & 0 & 0 & 0 & 0 \\
\hline & Total & 20 & 100 & 20 & 100 & 20 & 100 \\
\hline \multirow[t]{7}{*}{2} & Tingkat Pendidikan & & & & & & \\
\hline & Tidak tamat SD $(\infty<6$ tahun $)$ & 4 & 20 & 0 & 0 & 1 & 5 \\
\hline & Tamat SD ( $\infty 6$ tahun) & 10 & 50 & 12 & 60 & 14 & 70 \\
\hline & Tamat SMP ( $\infty 9$ tahun) & 2 & 10 & 3 & 15 & 2 & 10 \\
\hline & Tamat SMA ( $\infty 12$ tahun) & 4 & 20 & 0 & 0 & 2 & 10 \\
\hline & S1 $(\infty 16$ tahun $)$ & 0 & 0 & 5 & 25 & 1 & 5 \\
\hline & Total & 20 & 100 & 20 & 100 & 20 & 100 \\
\hline \multirow[t]{6}{*}{3} & $\begin{array}{l}\text { Jumlah Tanggungan Keluarga } \\
\text { (orang) }\end{array}$ & & & & & & \\
\hline & $0-1$ & 0 & 0 & 2 & 10 & 2 & 10 \\
\hline & $2-3$ & 12 & 60 & 14 & 70 & 14 & 70 \\
\hline & $4-5$ & 7 & 35 & 4 & 20 & 2 & 10 \\
\hline & $\geqslant 6$ & 1 & 5 & 0 & 0 & 2 & 10 \\
\hline & Total & 20 & 100 & 20 & 100 & 20 & 100 \\
\hline \multirow[t]{6}{*}{4} & Pengalaman Usaha HR (thn) & & & & & & \\
\hline & $0-10$ & 8 & 40 & 8 & 40 & 2 & 10 \\
\hline & $11-20$ & 7 & 35 & 6 & 30 & 14 & 70 \\
\hline & $21-30$ & 5 & 25 & 6 & 30 & 2 & 10 \\
\hline & $31-40$ & 0 & 0 & 0 & 0 & 2 & 10 \\
\hline & Total & 20 & 100 & 20 & 100 & 20 & 100 \\
\hline
\end{tabular}
pengalaman usaha tani disajikan pada Tabel 1 . Berdasarkan Tabel 1 diketahui bahwa usia responden di lokasi penelitian tergolong produktif yaitu usianya antara 20-69 tahun dimana responden terbanyak berusia antara 40-59 tahun. Kondisi ini menurut Susilowati dan Suhaeti (2012) tergolong usia produktif menengah dan tua. Melimpahnya tenaga kerja usia produktif memungkinkan perkembangan

Tabel 1. Karakteristik petani hutan rakyat di region atas, region tengah dan region bawah Kabupaten Ciamis

Sumber: Diolah dari data primer 2010 
hutan rakyat bisa berjalan lebih cepat karena usia produktif biasanya kreatif, inovatif, dan semangat berkaryanya tinggi. Petani di Kertaharja tergolong pekerja keras karena di usia yang relatif masih muda (20-29 tahun) sudah aktif mengelola hutan rakyat.

Lamanya petani mendapat pendidikan atau pelatihan bisa mempengaruhi usaha yang dijalankan. Senada dengan hal itu, Ichwandi (2001) menyampaikan bahwa tingkat pendidikan sangat mempengaruhi perilaku, pola pikir, dan respon masyarakat terhadap suatu informasi atau perubahan. Semakin tinggi tingkat pendidikan dan pengalaman seseorang pada umumnya akan semakin terbuka terhadap informasiinformasi yang berhubungan dengan usaha. Riddell dan Xueda (2012) menyatakan bahwa pendidikan formal meningkatkan penggunaan teknologi yang memungkinkan untuk menjalankan tugas-tugas yang lebih sulit. Sementara itu Sudaryanto et al. (1981) menyatakan bahwa tingkat pendidikan mempengaruhi tingkat upah. Rata-rata responden mendapat pendidikan di sekolah selama 7-8 tahun, sehingga menunjukkan bahwa seluruh responden tidak buta huruf. Rata-rata responden mendapat pendidikan paling lama ada di Kertajaya.
Jumlah tanggungan keluarga merupakan sumber tenaga kerja keluarga yang dapat berperan aktif dalam pengelolaan hutan rakyat. Rata-rata jumlah tanggungan keluarga berkisar antara 2-3 orang. Kecilnya ukuran keluarga ditambah minimnya modal menyebabkan rata-rata petani tidak mampu memelihara hutan dengan baik.

Pengalaman petani mengelola hutan rakyat di region atas dan region tengah berkisar antara 0-30 tahun tetapi mayoritas kurang dari 10 tahun. Petani di region bawah mempunyai pengalaman lebih lama yakni sampai dengan 40 tahun dan mayoritas lebih dari 10 tahun (10-20 tahun). Informasi tersebut menunjukkan bahwa responden sudah cukup lama bekerja di usaha hutan rakyat sehingga bisa dijadikan sebagai aset tersedianya tenaga kerja terampil. Lebih lamanya pengalaman petani di region bawah memperbesar peluang keberhasilan bagi pengembangan hutan rakyat di daerah itu.

\section{Pendapatan Petani}

Bagi petani hutan rakyat, usaha hutan rakyat pada umumnya menjadi sumber utama pendapatan, sedangkan pendapatan bisa menggambarkan tingkat

Tabel 2. Sumber pendapatan petani berdasarkan rata-rata luas lahan riil (region atas 0,774 ha; region tengah 2,078 ha; dan region bawah $0,727 \mathrm{ha}$ ).

\begin{tabular}{lcccccccc}
\hline \multirow{2}{*}{$\begin{array}{c}\text { Sumber } \\
\text { Pendapatan }\end{array}$} & \multicolumn{2}{c}{ Region Atas } & \multicolumn{2}{c}{ Region Tengah } & \multicolumn{2}{c}{ Region Bawah } & \multicolumn{3}{c}{ Kab. Ciamis } \\
\cline { 2 - 9 } & $\begin{array}{c}\text { Rata-rata } \\
\text { pendapatan } \\
\text { (Rp/thn) }\end{array}$ & $\%$ & $\begin{array}{c}\text { Rata-rata } \\
\text { pendapatan } \\
\text { (Rp/thn) }\end{array}$ & $\%$ & $\begin{array}{c}\text { Rata-rata } \\
\text { pendapatan } \\
\text { (Rp/thn) }\end{array}$ & $\%$ & $\begin{array}{c}\text { Rata-rata } \\
\text { pendapatan } \\
\text { (Rp/th) }\end{array}$ & $\%$ \\
\hline Hutan Rakyat & 6.641 .783 & 28 & 8.029 .358 & 34 & 6.302 .431 & 23 & 6.991 .191 & 28 \\
Jasa & 11.997 .778 & 51 & 7.229 .833 & 30 & 17.392 .667 & 63 & 12.206 .759 & 48 \\
Keluarga & 1.508 .333 & 6 & 5.659 .111 & 24 & 1.708 .667 & 6 & 2.958 .704 & 12 \\
Sawah & 1.081 .389 & 5 & 2.121 .065 & 9 & 1.510 .207 & 5 & 1.570 .887 & 6 \\
Hewan ternak & 1.760 .028 & 8 & 94.444 & 0,4 & 638.148 & 2 & 830.873 & 3 \\
Ikan & 405.667 & 2 & 794.157 & 3 & 41.667 & 0,2 & 413.830 & 2 \\
Total & 23.394 .977 & 100 & 23.927 .969 & 100 & 27.341 .689 & 100 & 24.888 .212 & 100 \\
\hline
\end{tabular}

Sumber: diolah dari data primer 2010 
kemampuan petani untuk berdaya beli dalam memenuhi kebutuhan hidupnya. Khususiyah et al. (2010) menyatakan bahwa pendapatan rumah tangga petani dapat mencerminkan keadaan ekonomi rumah tangganya. Tinggi rendahnya tingkat pendapatan rumah tangga dapat digunakan sebagai salah satu indikator tinggi rendahnya tingkat kesejahteraan suatu rumah tangga.

Tingkat pendapatan dipengaruhi oleh banyaknya jenis usaha yang dilakukan oleh petani. Berdasarkan data pada Tabel 2 diketahui bahwa pendapatan yang diperoleh berasal dari beberapa sumber usaha. Pendapatan tersebut diperoleh dari usaha yang dilakukan pada luas rata-rata hutan rakyat yang dikelola dan dari usaha lain yang dilakukan oleh responden selama satu tahun. Rata-rata luas garapan hutan rakyat di region atas adalah $0,774 \mathrm{ha}$; di region tengah 2,078 ha; dan di region bawah 0,727 ha.

Hasil analisis menunjukkan bahwa pendapatan yang paling besar dihasilkan dari hutan rakyat dan jasa dengan rata-rata berturut-turut $28 \%$ dan $48 \%$. Usaha berbasis lahan terutama hutan rakyat diakui responden sebagai pekerjaan utama karena hasilnya bisa mendukung kebutuhan harian maupun kebutuhan jangka panjang secara pasti. Seluruh responden mengaku bahwa profesi sebagai petani hutan merupakan pekerjaan yang diminati baik itu sebagai pekerjaan utama ataupun sampingan.

Di region tengah, pendapatan terbesar berasal dari hutan rakyat yaitu Rp 8.029.358 dengan kontribusi sebesar 34\%, sedangkan dari sektor jasa menempati urutan kedua yaitu Rp 7.229.833 dengan kontribusi sebesar 30\%. Hal ini disebabkan kondisi tempat tumbuh di region tengah sangat baik bagi usaha hutan rakyat. Sementara itu, di region tengah tidak terdapat sektor jasa yang potensial kecuali kebanyakan hanya berdagang atau jasa transportasi.

Perbedaan pendapatan antara petani di ketiga region terjadi karena beberapa faktor antara lain : adanya perbedaan rata-rata luas lahan yang digarap petani, juga karena adanya perbedaan harga kayu yang berkaitan dengan aksesibilitas. Topografi di region tengah relatif lebih landai dibandingkan dengan region atas sehingga biaya operasional pemanenan pohon lebih rendah. Tingginya pendapatan dari sektor jasa di region atas bersumber dari usaha dagang di kawasan obyek wisata Danau Panjalu sedangkan di region bawah terdapat usaha galian batu kapur. Sumber pendapatan yang lain seperti sawah, kolam ikan, ternak, dan usaha dari keluarga juga memberikan kontribusi namun kecil dan tidak rutin.

\section{Serapan Tenaga Kerja Keluarga Petani}

Berdasarkan data statistik desa dan kecamatan di lokasi penelitian, diketahui bahwa pekerjaan utama masyarakat adalah sebagai petani baik pemilik maupun buruh tani (Tabel 3). Kegiatan bertani tidak hanya sebagai petani lahan basah seperti sawah melainkan juga sebagai petani di lahan kering. Tingginya serapan tenaga kerja keluarga ini

Tabel 3. Penyerapan tenaga kerja rumah tangga petani hutan rakyat

\begin{tabular}{lccr}
\hline \multirow{2}{*}{ Rincian } & \multicolumn{3}{c}{ Region } \\
\cline { 2 - 4 } & Atas & Tengah & Bawah \\
\hline Jumlah KK & 2.004 & 995 & 1.582 \\
Jumlah RTPHR & 1.981 & 801 & 1.199 \\
Daya Serap RTPHR (\%) & 98,85 & 80,50 & 75,79 \\
\hline
\end{tabular}

Sumber : diolah dari data BPS, 2010

Keterangan: Rumah Tangga Petani Hutan Rakyat (RTPHR) dan Kepala Keluarga (KK) 
tergolong wajar karena pekerjaan sebagai petani masih dianggap sebagai bidang pekerjaan yang tidak memerlukan kualifikasi keahlian dan pendidikan tertentu. Padahal jika ditekuni, bertani bukanlah hanya perihal menanam pohon saja, tetapi juga termasuk sub-bidang turunannya seperti : memelihara lebah madu, mengembangkan jamur, membuat kompos, membuat arang dan lainnya. Semakin tinggi tingkat pendidikan petani semakin berkemampuan mengembangkan inovasi usaha taninya.

Pekerjaan di hutan rakyat umumnya dijalankan oleh ayah dan ibu, sedangkan anak sangat jarang terlibat. Pada umumnya anak-anak petani menempuh pendidikan sampai keluar desa, sehingga waktunya banyak tersita untuk urusan sekolah. Dukungan keluarga terhadap pendidikan cukup besar, terlihat dari besarnya pengeluaran responden yang menduduki peringkat ke-2 (dua) setelah pangan. Sebagian anak petani bahkan ada yang melanjutkan pendidikan hingga perguruan tinggi. Akan tetapi, pada umumnya mereka tidak mengabdikan ilmunya untuk membangun desanya dengan mengelola hutan melainkan bekerja di sektor lain.

Hutan rakyat dipandang sebagai bidang pekerjaan yang telah dimiliki keluarga sehingga untuk meningkatkan pendapatan, petani merasa perlu bekerja di sektor lain. Alasan tersebut mendorong anak-anak petani mencari pekerjaan di luar sektor hutan rakyat. Selain itu juga karena masih adanya persepsi bahwa pekerjaan sebagai petani hutan kurang bergengsi apalagi bagi anak muda.

Akibat dari kondisi tersebut adalah sumber tenaga kerja di hutan rakyat akan semakin berkurang. Tenaga kerja yang bekerja di sektor hutan rakyat pada akhirnya hanyalah tenaga kerja usia tua, seperti dilaporkan oleh Susilowati dan Suhaeti (2012) dimana tenaga kerja usia muda di Jawa Barat periode tahun 1983 sampai tahun 2000 pada sektor non-pertanian mencapai $47,1 \%$, sedangkan di sektor pertanian hanya $6,5 \%$. Sebaliknya untuk kelompok tenaga kerja usia tua bekerja di sektor non-pertanian hanya $7,3 \%$, sedangkan pada sektor pertanian $27,4 \%$. Jika kondisi ini dibiarkan terus berlangsung maka dikhawatirkan akan terjadi stagnasi pada perkembangan hutan rakyat karena usaha di bidang ini hanya ditekuni oleh petani yang termasuk pada usia tua. Pada kelas umur tersebut, petani biasanya mulai mengambil posisi aman yaitu bekerja hanya untuk memenuhi kebutuhan pokok jangka pendek saja (subsisten).

Meskipun curahan tenaga kerja pada sektor jasa di region bawah lebih besar dari sektor hutan rakyat tetapi pendapatan dari sektor jasa lebih kecil dari pendapatan di sektor hutan rakyat. Hal ini menunjukkan bahwa penghargaan terhadap jasa di region bawah lebih rendah dari region atas. Hal ini berkaitan dengan perbedaan tipe jasa dan target pasar yang ditawarkan dimana di region atas lebih menonjol konsumennya dari wisatawan, sedangkan di region bawah konsumen sektor jasa pada umumnya berasal dari rumah tangga.

Usaha hutan rakyat masih dianggap sebagai tabungan yang diperlukan pada saat tertentu saja (Awang et al., 2001; Purwanto et al., 2004) sehingga hutan rakyat hanya dipelihara seperlunya. Anggapan ini juga mengakibatkan hutan rakyat tidak diposisikan sebagai suatu bisnis yang bisa memberi pendapatan rutin sehingga sulit menjadikan hutan rakyat sebagai sumber utama pendapatan petani. Dampaknya adalah usaha hutan rakyat hanya dikelola dengan sistem manajemen keluarga dan belum sepenuhnya berorientasi bisnis.

\section{Curahan Tenaga Kerja Rumah Tangga Petani}

Selain lahan, modal, dan pengetahuan, tenaga kerja juga bagian dari faktor produksi pada 
pengelolaan hutan rakyat. Kemampuan petani dalam mengalokasikan tenaga kerja pada suatu usaha sangat menentukan keberhasilan usaha tersebut. Sumber tenaga kerja utama pada pengelolaan hutan rakyat biasanya berasal dari anggota keluarga petani, sedangkan perekrutan tenaga kerja dari luar keluarga dilakukan jika tenaga kerja dari anggota keluarga tidak mencukupi. Curahan tenaga kerja untuk seluruh usaha yang dilakukan diperlihatkan pada Tabel 4. Berdasarkan data pada Tabel 4 diketahui bahwa curahan tenaga kerja suami mendominasi semua bidang usaha yang dilakukan keluarga petani. Kondisi tersebut menunjukkan bahwa suami mempunyai peran ganda yakni sebagai kepala keluarga dan sebagai pengelola utama seluruh sektor usaha. Curahan tenaga kerja oleh tenaga kerja lainnya seperti istri, anak, dan buruh merupakan tenaga kerja tambahan yang diperlukan pada waktu tertentu saja.
Alokasi curahan tenaga kerja anak paling rendah untuk seluruh bidang usaha karena lebih diutamakan untuk kegiatan sekolah, sedangkan untuk kegiatan hutan rakyat biasanya dilakukan pada saat liburan sekolah. Hal ini akan menguatkan dugaan masih rendahnya minat dan motivasi anak untuk aktif terlibat di usaha hutan rakyat.

Pada umumnya tenaga kerja yang dicurahkan untuk mengelola hutan rakyat di region atas dan region tengah Kabupaten Ciamis lebih besar dibandingkan untuk mengelola sektor lainnya. Sebaiknya, tenaga kerja yang dicurahkan untuk mengelola hutan rakyat di region bawah Kabupaten Ciamis lebih rendah dibandingkan curahan tenaga kerja pada sektor jasa atau 152,73 HKP berbanding 163,06 HKP (Tabel 5). Akan tetapi, meskipun di region bawah tenaga kerja yang dicurahkan pada sektor hutan rakyat lebih rendah dibandingkan

Tabel 4. Curahan tenaga kerja petani dan keluarganya (HKP/Tahun).

\begin{tabular}{|c|c|c|c|c|c|c|c|}
\hline \multirow{3}{*}{ No } & \multirow{3}{*}{$\begin{array}{c}\text { Curahan TK di Usaha } \\
\text { yang Dilakukan }\end{array}$} & \multicolumn{6}{|c|}{ Region } \\
\hline & & \multicolumn{2}{|c|}{ Atas } & \multicolumn{2}{|c|}{ Tengah } & \multicolumn{2}{|c|}{ Bawah } \\
\hline & & $\mathrm{HKP} /$ th & $\%$ & $\mathrm{HKP} / \mathrm{th}$ & $\%$ & $\mathrm{HKP} /$ th & $\%$ \\
\hline \multirow[t]{7}{*}{1} & Hutan Rakyat & & & & & & \\
\hline & a. Suami & 107,54 & & 106,69 & & 115,81 & \\
\hline & b. Istri & 34,34 & & 69,57 & & 31,27 & \\
\hline & c. Anak & 3,68 & & 3,9 & & 0 & \\
\hline & d. Buruh & 22,29 & & 37,56 & & 5,65 & \\
\hline & $\begin{array}{l}\text { Total Curahan TK/ } \\
\text { rata-rata luas garapan }\end{array}$ & 167,84 & 55 & 217,72 & 45 & 152,73 & 42 \\
\hline & Total Curahan TK/ha & 216,93 & & 104,77 & & 210,05 & \\
\hline \multirow[t]{6}{*}{2} & Sawah & & & & & & \\
\hline & a. Suami & 7,63 & & 46,28 & & 33,87 & \\
\hline & b. Istri & 2,88 & & 14,45 & & 10,46 & \\
\hline & c. Anak & 0 & & 3,9 & & 0 & \\
\hline & d. Buruh & 0 & & 0 & & 0 & \\
\hline & Total Curahan TK & 10,51 & 3 & 61,74 & 13 & 44,33 & 12 \\
\hline \multirow[t]{6}{*}{3} & Jasa dan Lainnya & & & & & & \\
\hline & a. Suami & 92,56 & & 145,37 & & 113,01 & \\
\hline & b. Istri & 36,66 & & 50,73 & & 50,05 & \\
\hline & c. Anak & 0 & & 3,6 & & 0 & \\
\hline & d. Buruh & 0 & & 0 & & 0 & \\
\hline & Total Curahan TK & 129,22 & 42 & 199,69 & 42 & 163,06 & 45 \\
\hline \multicolumn{2}{|c|}{ Total $(1+2+3)$} & 307,57 & 100 & 479,15 & 100 & 360,12 & 100 \\
\hline
\end{tabular}

Sumber: diolah dari data primer 2010 
dengan sektor jasa, pendapatan dari sektor hutan rakyat lebih tinggi dari sektor jasa yakni Rp 8.956.809,- berbanding Rp 7.414.000,-. Hal ini menunjukkan bahwa tenaga kerja yang dicurahkan untuk mengurus hutan rakyat lebih bernilai dibandingkan dengan tenaga kerja yang dicurahkan ke jasa yakni Rp 58.645/HKP berbanding Rp 45.468/HKP. Dengan demikian, usaha hutan rakyat di region bawah menjadi sektor penting yang bisa dipergunakan sebagai pendorong untuk meningkatkan pendapatan petani. Salah satu modal penting di region bawah adalah petaninya merupakan pekerja keras dengan pengalaman berbisnis di bidang hutan rakyat lebih lama.

Untuk curahan tenaga kerja yang sama, pendapatan yang diperoleh petani dari sektor hutan rakyat di region atas lebih rendah daripada pendapatan yang diperoleh dari sektor jasa. Hal ini menunjukkan bahwa efisiensi tenaga kerja di bidang hutan rakyat rendah sehingga kurang mampu meningkatkan produktivitas hutan. Terkait dengan hal tersebut, keterampilan petani dalam mengelola hutan perlu ditingkatkan melalui pelatihan atau sekolah lapang. Curahan tenaga kerja akan berdampak signifikan terhadap produktivitas jika pembangunannya dipersiapkan secara intensif, menggunakan bibit yang unggul genetik, dan program penjarangan yang baik (Eriksson, 2004). Rendahnya pendapatan dari sektor hutan rakyat menurut Diniyati dan Fauziah (2011) disebabkan oleh beberapa hal, diantaranya : 1) rendahnya harga jual kayu di tingkat petani, 2) banyak pohon dijual yang belum mencapai umur tebang, 3) teknologi pengembangan hutan rakyat belum tepat, 4) pola budidaya hutan rakyat bersifat masih sederhana dan tradisional.

\section{Hubungan antara Curahan Tenaga Kerja dengan Karakteristik Petani}

Karakteristik petani yang berhubungan dengan curahan tenaga kerja antara lain umur petani, lama pendidikan/pelatihan petani, jumlah tanggungan, pengalaman berusaha di hutan rakyat, dan luas hutan. Untuk mengetahui hubungan karakteristik petani dengan curahan tenaga kerja pada setiap region digunakan persamaan regresi linier berganda dengan hasil sebagai berikut :

Region Atas, $\mathrm{Y}=109,287+1,44 \mathrm{X}_{1}+0,17 \mathrm{X}_{2}-0,75$ $\mathrm{X}_{3}+4,36 \mathrm{X}_{4}-99,84 \mathrm{X}_{5}$

Regresi (1) menunjukkan bahwa curahan tenaga kerja petani di hutan rakyat (Y) semakin tinggi jika umur petani $\left(\mathrm{X}_{1}\right)$, lamanya pendidikan $\left(\mathrm{X}_{2}\right)$, dan pengalaman bekerja di hutan rakyat $\left(\mathrm{X}_{4}\right)$ meningkat. Sebagai salah satu input produksi, peningkatan

Tabel 5. Nilai curahan tenaga kerja pada pengelolaan hutan rakyat dan sektor jasa

\begin{tabular}{llccc}
\hline No & \multicolumn{1}{c}{ Sumber Kegiatan } & Region Atas & Region Tengah & Region Bawah \\
\hline & & \multicolumn{3}{c}{ Sektor Hutan Rakyat } \\
& Luas rata-rata (ha)/\% garapan & $0.77 / 82,07 \%$ & $2,07 / 89,30 \%$ & $0,72 / 76,02 \%$ \\
\multirow{2}{*}{1} & Curahan tenaga kerja (HKP/th) & 167,84 & 217,72 & 152,73 \\
& Pendapatan (Rp/th) & 7.493 .232 & 11.180 .002 & 8.956 .809 \\
& Nilai satu HKP (Rp) & 44.645 & 51.350 & 58.645 \\
\hline \multirow{2}{*}{2} & Curahan tenaga kerja (HKP/th) & 129,22 & Sektor Jasa \\
& Pendapatan (Rp/th) & 9.334 .000 & 109,69 & 163,06 \\
& Nilai satu HKP (Rp) & 72.233 & 50.881 & 7.414 .000 \\
\hline
\end{tabular}

Sumber: diolah dari data primer 2010 
curahan tenaga kerja berpotensi meningkatkan pendapatan. Hal ini menggambarkan bahwa untuk memperoleh pendapatan yang tinggi dibutuhkan petani yang sudah matang dari segi usia dan pengalaman. Semakin lama petani mendapat pendidikan atau pelatihan, semakin terbuka wawasannya untuk mengembangkan kegiatan pada pengelolaan hutan rakyat ke dalam bentuk kegiatan turunannya sehingga curahan tenaga kerjanya juga meningkat.

Koefisien regresi variabel jumlah tanggungan keluarga $\left(\mathrm{X}_{3}\right)$ adalah negatif sehingga peningkatan tanggungan keluarga justru menyita curahan tenaga kerja dari usaha hutan rakyat. Hal ini disebabkan semakin banyak tanggungan keluarga berakibat pada semakin besarnya tingkat pengeluaran (kebutuhan) rumah tangga petani sehingga memaksa responden untuk memperoleh pendapatan yang lebih banyak. Akibatnya, curahan tenaga kerja petani akan terpecah menjadi dua bagian yaitu satu bagian untuk mengelola hutan rakyat dan satu bagian lainnya untuk mengelola sektor lain sehingga curahan tenaga kerja untuk sektor hutan rakyat akan semakin berkurang.

Selanjutnya, peningkatan luas garapan hutan rakyat $\left(\mathrm{X}_{5}\right)$ juga menyebabkan penurunan curahan tenaga kerja. Hal ini diduga ada kaitanya dengan faktor modal dan tenaga kerja yang dimiliki oleh responden. Kedua faktor tersebut merupakan pembatas, artinya petani hanya mengandalkan tenaga kerja yang ada di dalam keluarga dan pengembangan hutan rakyatnya dilakukan secara sederhana dengan meniadakan pemeliharaan. Hal ini menggambarkan bahwa walaupun hutan rakyat yang dimiliki luas namun untuk mengelolanya petani tidak mampu memenuhi kebutuhan jumlah curahan tenaga kerja yang optimal sehingga hutan rakyat banyak yang terlantar.
Region Tengah, $\mathrm{Y}=-380,17+8,47 \mathrm{X}_{1}+30,22 \mathrm{X}_{2}+$ $4,82 \mathrm{X}_{3}+0,48 \mathrm{X}_{4}-32,35 \mathrm{X}_{5}$

Variabel umur responden $\left(\mathrm{X}_{1}\right)$, lamanya pendidikan $\left(\mathrm{X}_{2}\right)$, jumlah tanggungan keluarga $\left(\mathrm{X}_{3}\right)$, dan pengalaman bekerja $\left(\mathrm{X}_{4}\right)$ mempunyai koefisien regresi bertanda positif. Hal ini berarti bahwa naik-turunnya nilai variabel-variabel tersebut akan menaikkan atau menurunkan curahan tenaga kerja. Akan tetapi, semakin luas hutan rakyat $\left(\mathrm{X}_{5}\right)$, semakin kecil curahan tenaga kerjanya. Artinya, walaupun hutan rakyat yang dimiliki luas curahan tenaga kerjanya relatif tetap sesuai ketersediaan tenaga kerjanya atau cenderung dibiarkan saja. Hal ini menjadi bukti yang menguatkan bahwa hutan rakyat pada umumnya hampir tidak pernah dipelihara, sehingga tanpa pengaturan pola tanam yang baik melalui sistem agroforestri, kesuburan tanah akan merosot tajam setelah tiga tahun penanaman (Mustofa, 2011).

Region Bawah, $\mathrm{Y}=66,69+7,03 \mathrm{X}_{1}-14,38 \mathrm{X}_{2}+0,01$ $\mathrm{X}_{3}-6,29 \mathrm{X}_{4}-39,25 \mathrm{X}_{5}$

Berdasarkan regresi (3), ada kecenderungan bahwa semakin lama petani di region bawah mendapat pendidikan $\left(\mathrm{X}_{2}\right)$, petani cenderung berusaha mencari pekerjaan di luar sektor hutan rakyat. Hal ini berkaitan dengan kebiasaan petani di region bawah melakukan migrasi ke Jawa Tengah sehingga mendapat akses informasi lebih luas tentang lapangan kerja lain selain sektor hutan rakyat. Hal inilah yang menyebabkan menurunnya curahan tenaga kerja di sektor hutan rakyat. Petani di region bawah mayoritas adalah pendatang dari Jawa Tengah yang di masa lalu direkrut sebagai pekerja oleh perkebunan kelapa. Tanggungan keluarga (X3) hampir tidak mempunyai pengaruh pada curahan tenaga kerja.

Semakin lama pengalaman bekerja di hutan rakyat $\left(\mathrm{X}_{4}\right)$ mengurangi curahan tenaga kerja pada pengelolaan hutan rakyat. Variasi jenis pekerjaan di 
sektor perkebunan lebih sempit dibandingkan di sektor hutan rakyat. Pekerja di perkebunan cenderung hanya melaksanakan kegiatan yang telah dijadwalkan sehingga naluri improvisasinya kurang berkembang. Semakin lama pengalaman bekerja dengan pola perkebunan menyebabkan petani semakin efisien memanfaatkan waktunya sehingga semakin kecil tenaga dicurahkan untuk mengurus hutan rakyat. Dampaknya juga terlihat bahwa pendapatan petani hutan rakyat di region bawah adalah paling rendah dibandingkan pendapatan petani hutan rakyat di region atas dan tengah.

Semakin luas hutan rakyatnya $\left(\mathrm{X}_{5}\right)$, semakin rendah tenaga kerja yang dicurahkan untuk mengelola hutan rakyat. Diduga hal ini berkaitan dengan terbatasnya jumlah tenaga kerja di dalam anggota keluarga dan modal yang dimiliki serta diperparah dengan kebiasaan tenaga kerja usia muda bermigrasi ke Jawa Tengah.

\section{KESIMPULAN}

Berdasarkan rata-rata luas riil hutan rakyatnya, tingkat pendapatan dari usaha hutan rakyat paling tinggi diperoleh petani di region tengah yakni 34\% dari total pendapatan petani. Hal ini disebabkan oleh lebih luasnya hutan yang dimiliki dan lebih banyaknya tenaga kerja terdidik. Pendapatan paling rendah dari pengelolaan hutan rakyat diperoleh petani di region bawah yakni hanya $23 \%$ dari total pendapatan petani. Hal ini diduga ada kaitannya dengan kebiasaan petani melakukan pekerjaan rutin ketika masih menjadi pekerja perkebunan kelapa di masa lampau sehingga kemampuan improvisasi dalam mengelola hutan rakyat sangat terbatas. Selain itu, juga cukup intensifnya petani usia muda melakukan migrasi ke daerah asal mereka (Jawa Tengah).
Curahan tenaga kerja keluarga di seluruh lokasi penelitian memiliki kesamaan pola yaitu tidak berhubungan dengan luas hutan yang dimiliki $\left(\mathrm{X}_{5}\right)$. Artinya, bahwa petani dari region atas sampai region bawah memiliki pola pengembangan yang sama yaitu hampir tidak pernah melakukan pemeliharaan. Sebaliknya, curahan tenaga kerja di seluruh lokasi penelitian berkorelasi positif dengan usia petani $\left(\mathrm{X}_{1}\right)$ yakni semakin tua usia petani, semakin banyak waktunya dicurahkan untuk mengelola hutan rakyat.

Untuk meningkatkan minat tenaga kerja produktif muda terhadap usaha hutan rakyat, diperlukan propaganda melalui media televisi yang dikemas secara menarik untuk menumbuhkan persepsi positif dan mengangkat gengsi usaha di bidang hutan rakyat terutama di kalangan tenaga muda. Salah satu cara untuk meningkatkan serapan tenaga kerja di sektor hutan rakyat adalah dengan menerapkan pola tanam agroforestri.

\section{DAFTAR PUSTAKA}

Attar M. 2000. Hutan rakyat; Kontribusi terhadap pendapatan rumah tangga petani dan perannya dalam perekonomian desa (Kasus di Desa Sumberejo, Kabupaten Wonogiri, Jawa Tengah). Dalam : Hutan Rakyat Di Jawa Perannya dalam Perekonomian Desa. Suharjito D (Ed). Program Penelitian dan Pengembangan Kehutanan Masyarakat (P3KM). Fakultas Kehutanan Institut Pertanian Bogor.

Awang SA, Santosa H, Widayanti WT, Nugroho Y, Kustomo, \& Sapardiono. 2001. Gurat Hutan Rakyat di Kapur Selatan. Debut Press. Jogjakarta.

BPS Kabupaten Ciamis. 2010. Kabupaten Ciamis dalam Angka Tahun 2010. Katalog BPS: 1403.3207. Badan Pusat Statistik Kabupaten Ciamis.

Diniyati D, Fauziyah E, Sulistyati T, Suyarno W, \& Mulyati E. 2010. Pola Agroforestri di Hutan Rakyat Penghasil Kayu Pertukanggan (Sengon). Laporan Hasil Penelitian Tahun 2010. Balai Penelitian Kehutanan Ciamis. 
Diniyati D \& Fauziyah E. 2011. Pengelolaan hutan rakyat oleh petani di Kabupaten Ciamis. Prosiding Workshop Status Riset dan Rencana Induk Penelitian Agroforestry. Pusat Penelitian dan Pengembangan Peningkatan Produktifitas Hutan. Bogor.

Darusman D. 2001. Resiliensi Kehutanan Masyarakat di Indonesia. Debut Press. Yogyakarta

Gontkovičová B, Bohuslava M, \& Michal P. 2015. Youth unemployment - current trend in the labour market? Procedia Economics and Finance 23, 1680-1685.

Ichwandi I. 2001. Dampak Krisis Ekonomi terhadap Usaha Kehutanan Masyarakat: Studi Kasus di Kab. Maros, Sulawesi Selatan. Dalam : Resiliensi Kehutanan Masyarakat di Indonesia. Darusman D (Ed). Debut Press. Jogjakarta.

Khan M, Saima A, Hafiz ZM, \& Kashif M. 2013. Analysing skills, education and wages in Faisalabad: Implications for labour market. Procedia Economics and Finance 5, 423-432.

Khususiyah N, Buana Y, \& Suyanto. 2010. Hutan Kemasyarakatan (HKm): Upaya Meningkatkan Kesejahtaeraan dan Pemerataan Pendapatan Petani Miskin di Sekitar Hutan. Brief No. 06 Policy Analysis Unit Juni 2010. World Agroforestry Centre.

Mustofa MS. 2011. Perilaku masyarakat desa hutan dalam memanfaatkan lahan di bawah tegakan. Jurnal Komunitas 3(1), 1-11.

Pujianto E. 2008. Analisis Penyerapan dan Curahan Tenaga Kerja Keluarga pada Usaha Peternakan Domba (Studi Kasus di Desa Cibunian Kecamatan Pamijahan dan Desa Cigudeg Kecamatan Cigudeg Kabupaten Bogor. Skripsi (Tidak dipublikasikan). Program Studi Sosial Ekonomi Peternakan Fakultas Peternakan. Institut Pertanian Bogor.

Purwanto SE, Wati \& Cahyono SA. 2004. Kelembagaan untuk mendukung pengembangan hutan rakyat produktivitas tinggi. Prosiding Ekspose Terpadu Hasil Penelitian, Yogyakarta 11- 12 Oktober 2004. Puslitbang Bioteknologi dan Pemuliaan Tanaman Hutan. 53-65.

Riddell WC \& Xueda S. 2012. The role of education in technology use and adoption : Evidence from the Canadian workplace and employee survey. Discussion Paper No 6377. IZZA. http://ftp.iza.org/dp6377.pdf. 10 September 2014 $(10.25)$
Subroto. 2013. Indonesia di Tanganmu : Persembahan Pemikiran bagi Generasi Muda Indonesia Menuju Indonesia 2045. Penerbit Buku Kompas, Jakarta.

Sudaryanto T, Saliem HP, \& Pasaribu S. 1981. Pola Penggunaan Tenaga Kerja di Pedesaan. Studi Kasus di Empat Desa Kabupaten Kudus dan Klaten, Jawa Tengah. Pusat Penelitian Agro Ekonomi. Badan Penelitian dan Pengambangan Pertanian. Departemen Pertanian.

Susilowati SH \& Suhaeti RN. 2012. Dinamika Ekonomi Pedesaan di Jawa Barat. http://pustaka.litbang.deptan.go.id/publikasi/wr2 41025.pdf. 28 Juni 2012 (9.35)

Simanjuntak T. 2007. Analisis Curahan Tenaga Kerja dan Pendapatan Petani Dafed pada Usahatani Padi Sawah. (Studi Kasus : Desa Karang Anyer, Kecamatan Gunung Maligas, Kabupaten Simalungun). Skripsi (Tidak dipublikasikan). Departemen Sosial Ekonomi Pertanian. Fakultas Pertanian. Universitas Sumatera Utara. Medan.

Vasile V \& Irina A. 2015. The educational level as a risk factor for youth exclusion from the labour market. Procedia Economics and Finance 22, 64-71. 